\title{
RESEARCH PAPER \\ PREVALENCE OF RED BLOOD CELL ANTIBODIES AMONG TRANSFUSED PATIENTS AT KOMFO ANOKYE TEACHING (KATH) HOSPITAL, GHANA
}

\author{
${ }^{*}$ L. A. Boateng ${ }^{1}$, H. Schonewille ${ }^{2}$, B. Sackey ${ }^{1}$, S. Owusu-Ofori ${ }^{3}$ and E. Afriyie ${ }^{3}$ \\ ${ }^{1}$ Department of Medical Laboratory Technology, KNUST, Kumasi, Ghana \\ ${ }^{2}$ Sanquin Blood Supply Foundation, Netherlands \\ ${ }^{3}$ Komfo Anokye Teaching Hospital, Kumasi, Ghana \\ *Corresponding author: akosboak@yahoo.com
}

\begin{abstract}
Red blood cell (RBC) alloimmunisation is a common problem in transfused patients because of the possibility of haemolytic reaction and limited availability of compatible blood. In highincome countries, pre-transfusion antibody screening is performed routinely. In Ghana, patients are transfused with $A B O R h$ ' $D$ ' compatible blood without screening for immune antibodies. We therefore studied the prevalence and specificities of RBC antibodies in transfused patients at Komfo Anokye Teaching hospital, Ghana. The study was cross-sectional, involving previously transfused patients who required another transfusion. Participants' basic data on demography and transfusion history were recorded. Blood samples were screened and subsequently typed for RBC antibodies using a column gel agglutination test. A total of 106 transfused patients, 52 male and 54 females were enrolled. The patients had previously received a median of $4 R B C$ units (range 1-14). Of these, ten patients (9.4\%) had 11 RBC alloantibodies, whose specificities were 2 anti-K; 2 anti-C; one each of anti-D, $-E,-M$, and $-S$; and 3 were pan-reactive. The number of transfusion episodes was significantly associated with the rate of alloimmunisation $(p=0.000)$. In conclusion the overall alloimmunisation rate in the study was $9.4 \%$ and this was significantly associated with increasing number of transfusion episodes. Antibodies were mainly directed against antigens in the Rhesus system and $K$ antigen. We recommend that antibody screening be incorporated into routine pre-transfusion testing procedures in Ghana.
\end{abstract}

Keywords: Alloimmunisation, multi transfusion, Alloantibody

\section{INTRODUCTION}

Transfusion therapy is vital in the management of patients with haematologic disorders and malignancies (Hoffbrand et al., 2005). For these patients, it is a life-saving intervention as they are often chronically anaemic after chemo- therapy and/or radiotherapy or usually require transfusion during illness. Although transfusion is life-saving, the development of antibodies against transfused foreign red blood cell (RBC) antigens (alloimmunisation) is one of the main risks associated with blood transfusion. 
The incidence of alloimmunisation is reported to be up to about $60 \%$ in chronically transfused patients which generally include patients with haemoglobinopathies, haematologic malignancies, organ transplant recipients and patients with renal failure (Schonewille et al., 1999; Angulo and Lima, 1999; Rosse et al., 1990). In other less transfused groups, alloimmunisation is between $1-10 \%$. The prevalence depends largely on how often antibody screening and identification were performed (Alves et al., 2012 ; Cheng et al., 2012 ; Schonewille et al., 2006 ; Santos et al., 2007; Melanie and Shulman, 2005 ; Aygun et al., 2002).

Factors such as number and frequency of transfusions (a measure of foreign antigen exposure), ethnic differences between recipient and donor (Gader et al., 2008; Shaz et al., 2008), immunogenicity of RBC antigens, recipient's sex (Murao and Viana, 2005), age (Winters et al., 2001), genetics (Noizat-Pirenne et al., 2006; Higgins and Sloan, 2008) and underlying disease (Bauer et al., 2007) have been found to influence alloimmunisation risk.

The risk of alloimmunisation increases with higher number of transfusions, however in multi-transfused patients most antibodies are formed after the first transfusions (Fluit et al., 1990; Schonewille et al., 1999; Zalpuri et al., 2012). Chronically transfused patients have about five times an increased risk of developing multiple antibodies (Schonewille et al., 2006) and are prone to developing autoantibodies which can lead to increased destruction of patients own red cells (Young et al., 2004). The most frequently encountered RBC antibodies are formed against the Rhesus and Kell blood group antigens (Schonewille et al., 1999; Heddle et al., 1995; Seyfried and Walewska, 1990).

In most high-income countries, patients are routinely tested for the presence of clinically important RBC antibodies before each transfusion event. Once an antibody is detected, the transfusion recipient is given compatible blood that is lacking the corresponding antigen(s), to prevent haemolytic transfusion reactions. In addition, a pre-emptive antigen $(\mathrm{Rh} / \mathrm{K})$ matching transfusion policy is often applied for chronically transfused patients and women in their (pre-) reproductive ages to reduce alloimmunisation.

In Ghana however, pre-transfusion screening involves only $\mathrm{ABO}$ and $\mathrm{Rh}$ " $\mathrm{D}$ " grouping and ABO compatibility testing, while antibody screening is not performed. To our best knowledge, no studies have been performed, addressing post-transfusion alloimmunisation among the Ghanaian population. As a result, not much is known about patients' antibody status and the effect of transfusion, despite the fact that alloimmunisation can significantly complicate transfusion therapy. The aim of this study was to determine the prevalence and specificities of RBC alloantibodies in previously transfused patients with different clinical conditions at Komfo Anokye Teaching Hospital, Kumasi, Ghana.

\section{METHODOLOGY \\ Study site}

The study was conducted at Komfo Anokye Teaching Hospital (KATH), in Kumasi, Ghana. Participants were recruited from the Medical, Dialysis, Oncology, Child Health, Surgery and Accident/Emergency Units of the hospital. KATH is the second largest and referral hospital in Ghana, serving five regions in the Northern sector of the country. It also provides specialized care to patients from neighbouring countries such as Burkina Faso, Togo, etc.

\section{Study population}

The study population included all patients over 2 years of age, with a transfusion request and with at least one previous blood transfusion episode. Written informed consent was obtained from participants 18 years and older and from guardians of those under 18 years.

\section{Inclusion criteria}

Patients over 2 years of age, with a transfusion request and with at least one previous blood 
transfusion episode.

\section{Exclusion criteria}

Patients below two years and patients who had never been transfused in their lifetime were excluded.

\section{Study design}

Participants' basic demographic features, number of transfusions, last transfusion episodes, clinical history and blood component requested were retrieved from patients' medical records and recorded on a questionnaire. Whole blood samples $(5 \mathrm{ml})$ were obtained from consenting patients for $\mathrm{ABO}, \mathrm{Rh}$ " $\mathrm{D}$ " grouping and antibody screening. ABO and Rh D blood grouping were performed using a manual tube method with monoclonal antisera A, B and D. Antibody screening and identification were performed at the Komfo Anokye Transfusion Medicine Unit (KA-TMU), using a three cell screen panel (Diacell I, II and III, DiaMed, Diamed Switzerland) in a low ionic strength indirect (LISS) anti-globulin test (Diamed Gel system, DiaMed-ID, Switzerland). Antibody identification was performed on all screen-positive samples using an extended 11-cell panel in LISS (DiaMed, Switzerland). Antibody specificities that could not be identified with the LISS technique were subjected to further testing with enzyme (papain)-enhanced cards, also from Diamed (Diamed Gel system, Dia-Med-ID, Switzerland).

\section{Ethical approval}

Ethical approval was obtained from the Committee on Human Research, Publication and Ethics, (CHRPE), School of Medical Sciences, Kwame Nkrumah University of Science and Technology in Kumasi, Ghana.

\section{Statistical Analysis}

Data were analyzed using SPSS version 16 for windows. Descriptive statistics were performed to summarize the patients' demographic and transfusion information. Chi square tests were performed to determine any possible association between factors (e.g. age, sex, number of previous transfusion episodes, disease groups) that may influence the outcome variable of interest (prevalence rate of alloimmunisation).

\section{RESULTS}

Between January and September 2013, a total of 106 consecutive patients (52 males and 54 females, Mean age 43.2 \pm 20.3 years, range 2-90 years) who had received at least one transfusion were recruited from 6 different clinical wards of KATH for antibody investigation. The highest proportion of samples screened was from the Medical (35.2\%) and surgical units (30.2\%) (Table 1). Almost $40 \%$ of patients had malignant disorders or renal disease. (Table 2). The patients had previously experienced a median of 4 RBC transfusion episodes (range 1-14; total 476) (Table 3). The current most frequent blood component requested was whole blood, while whole blood was issued in more than $80 \%$ of cases of a packed cell request (Table 3 ). The proportions of $\mathrm{ABO}$ blood groups of the patients were $52.7 \% \mathrm{O}, 25.9 \% \mathrm{~A}, 19.1 \% \mathrm{~B}$ and $2.3 \% \mathrm{AB}$ and $97.2 \%$ were $\mathrm{Rh}$ " $\mathrm{D}$ " positive.

In $10(9.4 \%)$ patients (median age 42.5years, range 13-60 years; male to female ratio $1: 1$ ), a total of $11 \mathrm{RBC}$ antibodies were detected. Of these, 8 had clear specificity and 3 were panreactive alloantibodies (Table 4). One immunized patient (female with anti-K) had experienced a single previous transfusion episode, 8 patients had received 3-6, and one patient 10 transfusion episodes, before antibody detection. There was a strong statistical association between the number of transfusion episodes and the rate of alloimmunisation $(\mathrm{p}=0.000)$, while other demographic features, age $(\mathrm{p}=0.983)$, gender $(\mathrm{p}=0.765)$ and clinical diagnosis $(\mathrm{p}=0.871)$, did not appear to influence alloimmunisation.

\section{DISCUSSION}

This was a pilot cross-sectional study undertaken to determine the prevalence and specificities of RBC alloantibodies in Ghanaian patients who received blood transfusions at KATH. Our results showed that $9.4 \%$ of patients were allo- 
30 Boateng et al.

Table 1: Proportion of patients from the various hospital units

\begin{tabular}{lcc}
\hline Hospital Units & Number & $(\%)$ \\
\hline Medicine & 38 & $(35.8)$ \\
Surgery & 32 & $(30.2)$ \\
Accident and Emergency & 7 & $(6.6)$ \\
Dialysis & 14 & $(13.2)$ \\
Oncology & 9 & $(8.5)$ \\
Child Health & 6 & $(5.7)$ \\
Total & $\mathbf{1 0 6}$ & $\mathbf{1 0 0}$ \\
\hline
\end{tabular}

Table 2: Disease types of patients and alloimmunisation characteristics

\begin{tabular}{llcccc}
\hline Disease types & $\begin{array}{l}\text { Patients } \\
\mathbf{n}(\%)\end{array}$ & $\begin{array}{c}\text { Total units } \\
\text { transfused } \\
(\mathbf{n})\end{array}$ & $\begin{array}{l}\text { Patients } \\
\text { with RBC } \\
\text { antibodies } \\
(\mathbf{n})\end{array}$ & $\begin{array}{l}\text { Immunized } \\
\text { patients by } \\
\text { disease (\%) }\end{array}$ & $\begin{array}{l}\text { Immunization } \\
\text { risk per unit } \\
\text { transfused (\%) }\end{array}$ \\
\hline Malignancy & $23(21.7)$ & 121 & 2 & 8.7 & 1.7 \\
Renal disease & $18(17.0)$ & 82 & 3 & 16.7 & 3.3 \\
Infectious diseases & $16(15.1)$ & 71 & 2 & 12.5 & 2.3 \\
Anaemia (unspecified) & $8(7.5)$ & 31 & 1 & 12.5 & 2.7 \\
Haemolytic condition* & $8(7.5)$ & 29 & 0 & 0 & 0 \\
Bleeding & $8(7.5)$ & 29 & 0 & 0 & 0 \\
Liver disease & $4(3.8)$ & 12 & 0 & 0 & 0 \\
Others** & $21(19.8)$ & 101 & 2 & 9.5 & 3.0 \\
\hline
\end{tabular}

* Sickle cell disease, hepatosplenomegaly with anaemia and Glucose-6-Phosphate dehydrogenase deficiency

${ }^{* * *}$ Vocal cord paralysis, neuropathic ulcers, head injury, fistulae, fractures, burst abdomen, diabetes, immune compromised state and unknown clinical diagnosis.

immunized, and the majority of antibodies were against antigens in the Rhesus blood group system. The alloimmunisation risk was associated with increasing number of transfusion episodes.

Our overall RBC alloimmunisation prevalence is in conformity with other published reports on patients receiving transfusion support for haematological and other non haematological disorders in both developing and developed countries (Natukunda et al., 2010; Shukla and Chaudhary, 1999). Most of our antibody specificities identified are similar to antibodies commonly encountered and reported in other pub- 
Table 3: Demographic and transfusion characteristics of RBC alloimmunized and non alloimmunized patients

\begin{tabular}{lll}
\hline $\begin{array}{l}\text { Demographic and transfusion } \\
\text { characteristics of patients }\end{array}$ & $\begin{array}{l}\text { RBC alloimmunized } \\
\text { patients }(\mathbf{n = 1 0})\end{array}$ & $\begin{array}{l}\text { Non-immunized patients } \\
(\mathbf{n = 9 6})\end{array}$ \\
\hline $\begin{array}{l}\text { Median age in years (range) } \\
\text { Mean age in years } \pm \text { SD }\end{array}$ & $\begin{array}{l}42.5(13-60) \\
40.2 \pm 15.0\end{array}$ & $43.0(2-90)$ \\
& $1: 1$ & $\sim 1: 46 \pm 20.8$ \\
Sex ratio (F:M) & $4(1-10 ; 41)$ & $4(1-14 ; 435)$ \\
$\begin{array}{l}\text { Median previous transfusion episodes } \\
\text { (range; total) }\end{array}$ & & \\
Current transfusion request: & $5(50)$ & $50(55.6)$ \\
Whole blood request (\%) & $5(50)$ & $40(44.4)$ \\
Erythrocyte concentrate request $(\%)$ & $8(80)$ & $84(93.3)$ \\
Whole blood transfused (\%) & & \\
\hline
\end{tabular}

The number of whole blood and erythrocyte requests in non-immunized patients do not add up to 96, because for 6 patients the current request was for fresh frozen plasma $(n=2)$, platelet concentrate $(n=3)$ and plasma + platelets $(n=1)$.

Table 4: Red blood cell antibody specificities identified in 10 immunized patients

\begin{tabular}{lcc}
\hline Antibody specificity by blood group system & Number & $(\boldsymbol{\%})$ \\
\hline D, C, E & $1,2,1$ & $(36.4)$ \\
K & 2 & $(18.1)$ \\
M, S & 1,1 & $(18.1)$ \\
Pan-reactive & 3 & $(27.3)$ \\
\hline
\end{tabular}

lished studies (Santos et al., 2007; Alves et al., 2012), again confirming the high frequency of antibodies against Rhesus system antigens.

Alloantibodies production in our study was mainly found in patients with more than two transfusion episodes but one patient developed an antibody after a single episode. This finding suggests that even a single non antigenmatched transfusion may be enough to develop alloantibodies. One patient who had five transfusion episodes produced two antibodies. This is consistent with a report of Schonewille et al. (2006), which found that multi-transfused patients are at high risk of developing multiple antibodies. The D antibody was unexpected since the patient was an $\mathrm{Rh}$ ' $\mathrm{D}$ ' positive male. Similar findings have been reported by others (Chou et al., 2013; Natukunda et al., 2011). Although further D genotyping was not done, this patient may have a D variant, lacking certain epitopes to which the antibody was formed.

Our findings suggest alloimmunisation is not 


\section{Boateng et al.}

influenced by age, gender and clinical diagnosis. This finding is in agreement with other studies including Usman et al., (2011) and Higgins and Sloan (2008). However, Winters et al. (2001), Bauer et al. (2007) and Verduin et al. (2012), observed contrasting results. This disparity may be due to the difference in sample size and population. We confirmed a significant association between number of transfusion episodes and alloimmunisation (Natukunda et al.,2010 and Zalpuri et al., 2012).

Although most common transfusion practice in the western world is blood component therapy (UM, 2011), in Ghana close to $60 \%$ of its blood requests is whole blood. Even though $45 \%$ of the request was packed cell, patients were administered whole blood in about $80 \%$ of these cases. This may be due to lack of required human expertise and appropriate equipment to aid large scale preparation of blood components from whole blood. This does not offer maximum benefit to be derived from a unit of donated blood and may be a contributory factor to Ghana's inability to meet the units of blood required for transfusion daily (Ghana Health Nest, 2014). Patients receiving whole blood in the absence of available packed cells end up receiving components they do not need, whereas this could have been stored for patients who may need them in the future.

\section{LIMITATIONS OF STUDY}

- Some patient information were not fully captured, making it difficult for us to determine the total number of transfusion units patients had received.

- The exact moment of immunization was unknown as antibody screening was not performed prior to each transfusion.

\section{CONCLUSION AND RECOMMENDA- TION}

Overall, alloimmunisation prevalence rate among patients in this study was $9.4 \%$. Although this may be lower than what is reported in literature, it is very significant, considering the fact that Ghana's population is fairly homogenous. It is therefore necessary to expand the study to cover all the major regional and teaching hospitals in Ghana where chronically transfused patients are managed. We also recommend that antibody screening and identification tests are incorporated in the routine pretransfusion testing procedures so that patients who develop antibodies can be issued antigennegative blood.

\section{ACKNOWLEDGEMENTS}

The authors wish to thank Abednego Arthur, Joshua Asante and Kwabena Ameyaw Boateng of KATH Blood Bank, for the help in recruiting and drawing of blood samples. The Grants and Research Office of College of Health Sciences, KNUST, is also acknowledged for providing funds for the study.

\section{CONFLICT OF INTEREST}

All authors declare no conflict of interest.

\section{REFERENCES}

Alves, V. M., Martins, P. R., Soares, S., Araújo, G., Schmidt, L. C., Costa, S. S., Langhi Júnior, D. M. and Moraes-Souza, H. (2012). Alloimmunisation screening after transfusion of red blood cells in a prospective study. Revista Brasileira de Hematologiae Hemoterapia, 34: (3)206-211

Angulo, I. L. and Lima, E. G. (1999). Antierytrocyte antibodies in hemodialysis and kidney transplant patients. Renal Failure, 21:483-486.

Aygun, B., Padmanabham, S., Paley, C. and Chandrasekaran, V. (2002). Clinical significance of RBC alloantibodies and autoantibodies in sickle cell patient who received transfusions. Transfusion, 42:37-43.

Bauer, M. P., Wiersum-Osselton, J., Schipperus, M., Vandenbroucke, J. P. and Briet, E. (2007). Clinical predictors of alloimmunisation after red blood cell transfusion. Transfusion, 47:2066-2071. 
Cheng, C. K., Lee, C. K.and Lin, C. K. (2012). Clinically significant red blood cell antibodies in chronically transfused patients: a survey of Chinese thalassemia major patients and literature review. Transfusion, 52 (10):2220-4

Chou, S. T., Jackson, T., Vege, S., SmithWhitley, K., Friedman, D. F. and Westhoff, C. M. (2013). High prevalence of red blood cell alloimmunisation in sickle cell disease despite transfusion from Rh-matched minority donors. Blood, 122: 1062-1071.

Fluit, C. R. M. G., Kunst, V. A. and DrentheSchonk, A. M. (1990). Incidence of red cell antibodies after multiple blood transfusions. Transfusion, 30:530-535

Gader, A. G., Al Ghumlas, A. K.and ALMomen, A. K. (2008). Transfusion medicine in developing country-alloantibodies to red blood cells in multi-transfused patients in Saudi Arabia. Transfusion and Apheresis Science, 39:199-204

Ghana Health Nest, (2014). Acute Blood Shortage hits National Blood Center. Ghana, Healthcare, Korle $\mathrm{Bu}$ Teaching Hospital: http://ghanahealthnest.com/2014/01/10/ghana -acute-blood-shortage-hits-national-bloodcenter/ accessed on $8^{\text {th }}$ January 2015.

Heddle, N. M., Soutar, R. L., O'Hoski, P. L., Singer, J., McBride, J. A., Ali, M. A. M. and Kelton, J. G. (1995). A prospective study to determine the frequency and clinical significance of alloimmunisation post transfusion. British Journal of Haematology, 91:10001005.

Higgins, J. M. and Sloan, S. R. (2008). Stochastic modeling of human RBC alloimmunisation: Evidence for a distinct population of immunologic responders. Blood, 112 (6):2546-2553.

Hoffbrand, A. V., Moss, A. H. and Pettit, J. E.
(2005). Essential Haematology. 5th Edition Blackwell Publishing, Oxford.

Melanie, O. and Shulman, I. A. (2005). Phenotype matching of donor red blood cell units for non alloimmunized sickle cell disease patients: A Survey of 1182 North American Laboratories. Archives of Pathology and Laboratory Medicine, 129 (2) 190-193.

Murao, M. and Viana, M. B. (2005). Risk factors for alloimmunisation by patients with sickle cell disease. Brazilian Journal of Medical and Biological Research, 38(5): 675 $-682$

Natukunda, B., Schonewille, H., Ndugwa, C. and Brand, A. (2010). Red blood cell alloimmunisation in sickle cell disease patients in Uganda. Transfusion, 50 (1):2025 .

Natukunda B, Mugyenyi G, Brand A. and Schonewille, H. (2011). Maternal red blood cell alloimmunisation in south western Uganda. Transfusion Medicine, 21(4):262266.

Noizat-Pirenne, F., Tournamille, C., Bierling, P., Roudot-Thoraval, F., Pennec, P. Y. L., Rouger, P. and Ansart-Pirenne, H. (2006). Relative immunogenicity of Fya and $\mathrm{K}$ antigens in a Caucasian population based on HLA class II restriction analysis. Transfusion, 46(8):1328-1333.

Rosse, W. F., Gallagher, D., Kinney, T. R., Castro, O., Dosik, H., Moohr, J., Wang, W. and Levy, P. S. (1990). Transfusion and alloimmunisation in sickle cell disease. The Cooperative Study of Sickle Cell Disease. Blood, 76:1431-1437.

Santos, F. W., Magalhães, S. M., Mota, R. M. and Pitombeira, M. H. (2007). Posttransfusion red alloimmunisation in patients with acute disorders and medical emergencies. Revista Brasileira de Hematologiae 


\section{Boateng et al.}

Hemoterapia, 29(4):369-372.

Schonewille, H., Haak, H. L. and Van Zijl, A. M. (1999). Alloimmunisation after blood transfusion in patients with hematologic and oncologic diseases. Transfusion, 39:763-771.

Schonewille H., Van de Watering, L. M. G., Loomans, D. S. E. and Brand, A. (2006). Red blood cell alloantibodies after transfusion:: factors influencing incidence and specificity. Transfusion, 45: 250-256.

Seyfried, H. and Walewska, I. (1990). Analysis of immune response to red blood cell antigens in multi-transfused patients with different diseases. Materia Medica Polona, 22:2125.

Shaz, B. H., Zimring, J. C., Demmons, D. G. and Hillyer, C. D. (2008). Blood donation and blood transfusion: Special considerations for African Americans. Transfusion Medicine Reviews, 22:202-214.

Shukla, J. S. and Chaudhary, R. K. (1999). Red cell alloimmunisation in multi-transfused chronic renal failure patients undergoing hemodialysis. Indian Journal of Pathology and Microbiology, 42: 299-302.

University of Michigan (2011) chapter 4 blood c o m p o n e $\mathrm{n} \mathrm{t} \quad \mathrm{h} \mathrm{t} \mathrm{t} p: / /$ www.pathology.med.umich.edu/bloodbank/ manual/bbch_4/ Assessed on 6/13/2014.
Usman, M., Moin, S., Moinuddun, M., Ahmad, S., Perveen, R., Azmi, M. A. and Usman, S. (2011). Frequency of red cell alloimmunisation among patients with transfusion dependent beta thalassemia in Pakistan. International Journal of Haematology and Oncology, 3(21): 166-169.

Verduin, E. P., Brand, A. and Schonewille, H. (2012). Is female sex a risk factor for red blood cell alloimmunisation after transfusion? A systematic review. Transfusion Medicine Review, 26:342 -353

Winters, J. L., Pineda, A. A., Gorden, L. D., Bryant, S. C., Melton, L. J., Vamvakas, E. C. and Moore, B. S. (2001). RBC alloantibody specificity and antigen potency in Olmsted County, Minnesota. Transfusion, 41: 14131420

Young, P. P., Uzieblo, A., Trulock, E., Lublin, D. M. and Goodnough, L. T. (2004). Autoantibody formation after alloimmunisation: are blood transfusions a risk factor for autoimmune haemolytic anemia? Transfusion, 44:67-72.

Zalpuri, S., Zwaginga, J. J., Le Cessie, S., Elshuis, J., Schonewille, H. and Van der Bom, J. G. (2012). Red-blood-cell alloimmunisation and number of red-blood-cell transfusions. Vox Sanguinis, 102 (2):144-149. 